\title{
Treatment of Shear Stress versus Shear Rate Data for Natural Fiber Reinforced Polymer Composites: A Discussion
}

\author{
K. Begum ${ }^{1 *}$, M. A. Islam ${ }^{2}$ \\ ${ }^{1}$ Department of Physics, Shahjalal University of Science and Technology (SUST), Sylhet-3114, \\ Bangladesh \\ ${ }^{2}$ Department of Chemical Engineering and Polymer Science, Shahjalal University of Science and \\ Technology (SUST), Sylhet-3114, Bangladesh
}

Received 22 April 2018, accepted in final revised form 29 October 2018

\begin{abstract}
The rheological properties of melt jute fiber reinforced polypropylene (PP) composites were conducted at constant shear stress. The measured shear stress and shear rate data are fitted to a power law model for measuring stress-independent melt viscosity of the composites. The viscosity increased with the increase of fiber loading and decreased with the rise of temperature. The flow behavior index, $n$ was found to decrease with the increase of fiber loading and increase with the rise of temperature. The shear stress and shear rate data collected from different specialized research journals have also been fitted to the power law model to measure the stress-independent melt viscosity and flow index as in all the previous literatures viscosity is treated as stress dependent parameter. It was found that the dependence of the viscosity and the flow index observed from previous literature data with fiber loading and temperature was quite consistent with the present study.
\end{abstract}

Keywords: Polymer composites; Rheology; Melt viscosity; Flow index; Power law model.

\section{Introduction}

In recent years, natural fiber reinforced polymer composites (NFRPC) have received considerable attention both in the literature and in industrial applications due to their improved mechanical properties, significant processing advantages, low cost and low density $[1,2]$. Improved mechanical properties can be achieved with the addition of natural fiber of different origins to a neat polymer [3,4-8]. The processing and shaping of polymeric materials is a process of deformation, flow and solidification of materials. During processing and shaping, the polymeric materials pass through molten state. In this

\footnotetext{
* Corresponding author: china@ sust.edu
} 
case, various mechanical responses will be produced, and complex non-Newtonian properties will appear. The rheological behavior of the polymeric materials is important for selecting the processing conditions for the fabrication of polymer products. A number of investigations on the rheological behavior of short fiber-reinforced thermoplastics have been reported in literature. Mohanty et al. [9] investigated the variation of melt viscosity of the untreated and treated jute-fiber-reinforced polypropylene composites at varying fiber content at a fixed temperature. In the investigation it was observed that the viscosity of the systems increased with the increase of fiber loading. It was also observed that the incorporation of chemically treated fibers into the composition resulted in higher viscosity of the composites than that of untreated composites. The variation in the viscosity of wood flour reinforced polypropylene composites with the variation in fiber loading and temperature was studied by Maiti et al. [10]. They reported that the viscosity increased with the increase of fiber loading but decreased with the increase of temperature. George et al. [11] observed the same temperature- and fiber loading-dependence of viscosity for both the treated and the untreated short pineapple fiber reinforced low density polyethylene (LDPE) composites as Maiti et al. [10] did for wood flour reinforced polypropylene composites. Introduction of chemically treated fibers into the composition resulted in higher viscosity of the melt composites than that of untreated ones. The variation in the viscosity of the short-sisal-fiber-reinforced styrene butadiene rubber (SBR) composites with the variation in temperature and fiber loading as observed by Prasantha et al. [12] was also similar to that done by George et al. [11] for short pineapple fiber-LDPE composites. Joseph et al. [13] observed that the viscosity of short sisal fiber reinforced polypropylene composites increased with the increase in the fiber content. Under identical shear rate, composites with chemically treated fiber showed higher viscosity than those with untreated ones.

In the present work, the rheological behavior of jute-fiber-filled polypropylene melt composites has been studied. The plan of this work is to investigate the effect of fiber loading and temperature on the melt viscosity of jute-fiber-reinforced polypropylene composites. In all the previous literature the viscosity of the polymer composites has been treated as a stress-dependent parameter [10-13]. But similar to our previous study [14] in this work also the melt viscosity is treated as a stress-independent parameter. During this study we also treated the shear stress versus shear rate data obtained from various specialized research journals $[10,11,15]$ for the calculation of stress-independent melt viscosity and to draw a comparison with the present data.

\section{Experimental}

\subsection{Materials}

Polypropylene (PP) with density $881.8 \mathrm{~kg} / \mathrm{m}^{3}$ and melt flow index of $10.56 \mathrm{~g} / 10 \mathrm{~min}$ at $220^{\circ} \mathrm{C}$ and $2.03 \mathrm{~kg}$ used as the base polymer matrix was purchased from local market, Dhaka. The Jute fibers used as reinforcing agent in composites were also collected from the local market. The average molecular weight of PP was estimated by correlating the 
melt flow index with the average molecular weight through empirical relations developed by Ferg et al. and Bremner et al. [16,17] and it was found to be $20000-300000 \mathrm{~g} / \mathrm{mol}$.

\subsection{Treatment of fibers}

To remove the dirt eventually adhered to the fibers, the material was soaked in a detergent solution at $70{ }^{\circ} \mathrm{C}$ for $30 \mathrm{~min}$. Then the fibers were washed several times with tap water and finally by distilled water. The washed fibers were then dried at open air for seven days and subsequently in an electric oven at $105^{\circ} \mathrm{C}$ for two $\mathrm{h}$. The fibers were chopped to make short fibers manually (roughly $2-8 \mathrm{~mm}$ ). These detergent-treated fibers were then used for making composites.

\subsection{Preparation of composites}

Polypropylene/jute composites containing 0, 10, 20 and $30 \mathrm{wt} \%$ jute fibers were prepared by melt mixing technique. In the melt mixing method, the fiber was added to a melt of polypropylene and the mixing was performed in a double roller open mixer machine (Product of Dong Guang LiNa Machinery Industrial Co., LTD) for $1 \mathrm{~h}$ at $145^{\circ} \mathrm{C}$. The composite was then taken from the mixer and dried in open air and cut into small sizes suitable for loading inside the barrel of the extrusion assembly for rheological measurements.

\subsection{Rheological measurements}

Rheological measurements of jute fiber reinforced PP composites were carried out by a melt flow index tester-auto cutter (supplied by International Equipments Company, Ltd. India) adapted for the purpose at a applied wall shear stress range of (1.0-4.4) $\times 10^{4} \mathrm{~Pa}$ at 220-260 ${ }^{\circ} \mathrm{C}$. The melts polymer composites are forced to flow by a piston under a given predetermined pressure through a capillary die. Raw data in a capillary are the volumetric flow rate $Q$ and the required pressure drop $P$ across the die length at a given temperature. The flow rate and the pressure drop are converted to shear rate and shear stress by a wellknown procedure.

The wall shear stress was calculated as [18]:

$$
\tau_{w}=\frac{P R}{2 L}
$$

Where $P$ is the pressure drop, $L$ is the length of the capillary and $R$ is the radius of the capillary.

For Newtonian fluids, the wall shear rate is given as [18]:

$$
\dot{\gamma}_{w, N}=\frac{4 Q}{\pi R^{3}}
$$


The subscript $N$ is used to denote shear rate for fluids exhibiting Newtonian flow behavior and $Q$ is the flow rate through the capillary tube.

Therefore, for Newtonian fluids, the wall shear rate is related to the wall shear stress through the following relation [14].

$$
\frac{P R}{2 L}=\mu\left(\frac{4 Q}{\pi R^{3}}\right)
$$

Where $\mu$ is the viscosity of the fluids.

On the other hand, the derivation of the wall shear rate is slightly more complex in the case of non-Newtonian fluids and is given by the following relation [14]. The detailed procedure for the derivation of this parameter is not presented here; only the final equation is given.

$$
\dot{\gamma}_{w, n o n-N}=\left(\frac{4 Q}{\pi R^{3}}\right) \frac{3 n+1}{4 n}
$$

Where $n$ is the flow behavior index and the factor $(3 n+1) / 4 n$ is called by some authors to be Ravinovich correction $[11,12,15]$.

Therefore, for non-Newtonian fluids shear stress is related to the shear rate by a power law, then

$$
\frac{P R}{2 L}=\mu\left(\frac{4 Q}{\pi R^{3}} \cdot \frac{3 n+1}{4 n}\right)^{n}
$$

The Eq. (5) can be linearized as follows

$$
\ln \left(\frac{P R}{2 L}\right)=\ln \left[\eta\left(\frac{3 n+1}{4 n}\right)^{n}\right]+n \ln \left(\frac{4 Q}{\pi R^{3}}\right)
$$

A $\ln (P R / 2 L)$ vs. $\ln \left(4 Q / \pi R^{3}\right)$ plot would give the value of $\eta$ and $n$.

\subsection{Extrudate morphology}

The optical photographs of the surface and cross-section of the extrudates were studied using optical microscope. The extrudates were fracture by a sharp knife to study the morphology of the extrudates cross section. 


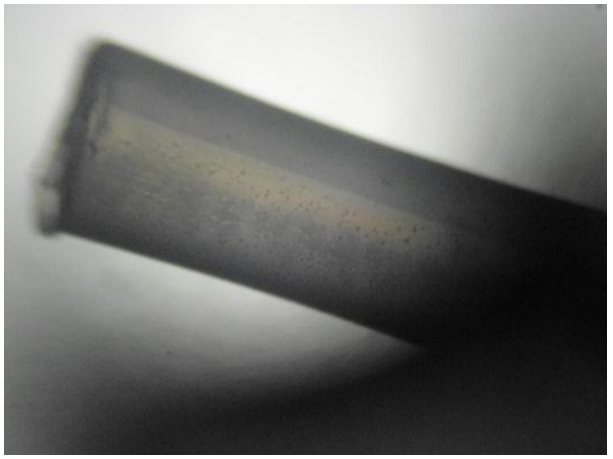

(a)



(b)

Fig. 1. Optical photographs of the surface of the extrudates at the constant shear stress of $9.54 \times 10^{3}$ $\mathrm{Pa}$ and the temperature of $220^{\circ} \mathrm{C}$ : (a) PP and (b) $20 \mathrm{wt} \%$ jute fiber reinforced PP composite.

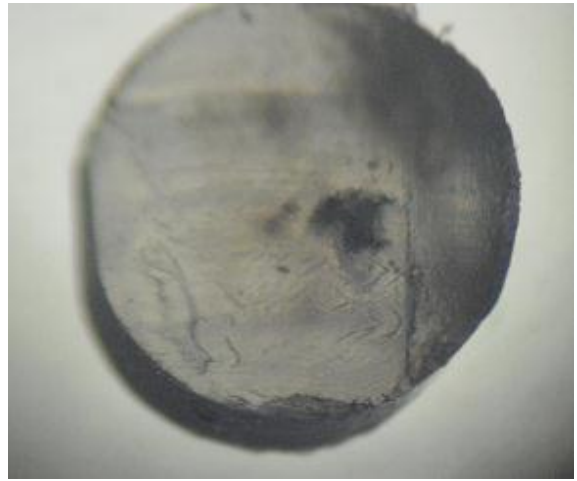

(a)

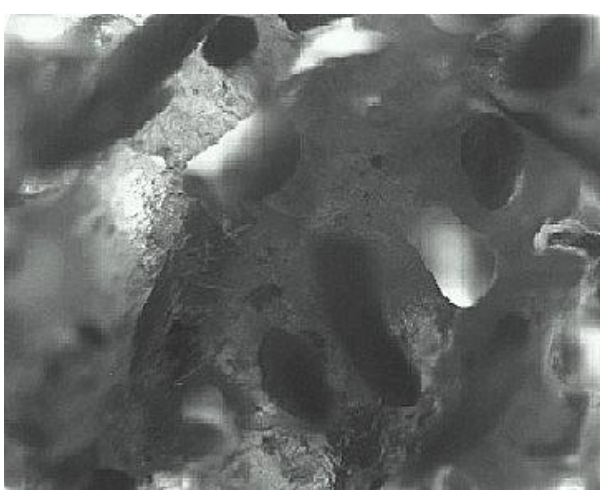

(b)

Fig. 2. Optical photographs of the cross-section of the extrudates at the constant shear stress of $9.54 \times 10^{3} \mathrm{~Pa}$ and the temperature of $220{ }^{\circ} \mathrm{C}$ : (a) $\mathrm{PP}$ and (b) $20 \mathrm{wt} \%$ jute fiber reinforced $\mathrm{PP}$ composite.

\section{Results and Discussion}

\subsection{Treatment of shear rate versus shear stress data}

Fig. 3 presents the shear rate as a function of applied shear stress at the temperature of 220 ${ }^{\circ} \mathrm{C}$. The shear rate is calculated with the assumption that the melt shows Newtonian flow behavior. The Eq. (3) represents such relation with a constant viscosity independent of shear stress, and for the validity of the model, the shear rate vs. applied shear stress relation should appear linear with the slope equal to $1 / \eta$. As seen from the Fig., the experimental relation is not linear and the slope increases as the shear stress increases. So the apparent viscosity of the composites decreases as the inverse of the slope measures the 
viscosity. This is a typical non-Newtonian behavior and the data should be fitted to some non-linear model.

\subsection{Flow behavior index (FBI), $n$}

Fig. 4 also presents the shear stress as a function of shear rate at the wall at $220{ }^{\circ} \mathrm{C}$; but this time the shear rate is calculated with the assumption that the melt flow follows power law model. The shear rate vs. applied shear stress relation then is represented by Eq. 6 . The data fit to the power law model quite satisfactorily. The slope of the straight lines measures the flow behavior index of jute-fiber-reinforced polymer composites of various fiber concentrations. Similar figures were drawn from the flow data obtained from the experiments at 240 and $260{ }^{\circ} \mathrm{C}$ (not shown in the paper for brevity). Figs. 5-7 were also drawn from the flow rate data obtained from the different specialized research journals $[10,11,15]$ for PP-wood flour composites, LDPE- short pineapple fiber composites, PSsisal fiber composites, respectively for measuring the flow behavior index, $n$ to draw a comparison with the present investigation. Table 1 shows variation of $n$ with fiber content and the operational temperature for the present study and it is found that the index $n$ is practically independent of temperature; but shows somewhat slightly decreasing trend with the increase of the fiber content. Table 2 gives the value of $n$ (measured from the treated data of previous literatures) for different fiber reinforced polymer composites. From Table 2 it is also seen that the value of $n$ decreased with the increase of fiber concentration for a particular temperature for each composite except for polystyrene (PS) sisal fiber composites [15]. In case of PS sisal fiber composites [15] an anomalous change in flow behavior index, $n$ was found with the increase with fiber concentration. This was explained by previous author [15]. For jute fiber PP composites, $n$ is found to be in the range of $\quad 0.6-0.7$ for 0-30 wt\% fiber content whereas for LDPE- short pineapple fiber composites [11], PS sisal fiber composites [15], and PP-wood flour composites [10] this parameters are found to be in the range of $0.3-0.4,0.2-0.4$ and $0.3-0.4$ respectively for the fiber content range of 0-30 wt $\%, 0-30 \mathrm{wt} \%$ and $0-20 \mathrm{wt} \%$. Actually the variation in flow behavior index, $n$ arises due to the types of fiber and fiber content, polymer types, operational temperature and wall shear stress or wall shear rate. But for all composites, discussed above $n$ has the decreasing trend with the increase of fiber content which meant that the non-Newtonian nature of the fiber reinforced composites increased with the increase of fiber content.

\subsection{Effect of temperature and fiber loading on melt viscosity}

As the shear stress vs. shear rate relation is satisfactorily represented by Eq. 6, the intercept of the straight lines drawn in Figs. 4-7 appears to be a measure for the melt viscosity $\eta$, and as seen from the figures, it increases with an increase in the fiber content. With the observed value of $n$ (Table 1), the value of the viscosity $\eta$ (stress independent) of PP jute composites at $220{ }^{\circ} \mathrm{C}$ is calculated from the expression of the intercept in Eq. (6). The same procedure is followed for the determination of the viscosity at 240 and $260{ }^{\circ} \mathrm{C}$. 
The viscosity data obtained at different temperatures is summarized in a Table 3 . Using the measured value of $n$ from the literature data the values of the melt viscosity $\eta$ of short pineapple fiber reinforced LDPE composites, PP wood flour composites and PS sisal fiber composites are also calculated from the expression of the intercept in Eq. (6). The viscosity data calculated from the collected shear rate data is inserted in a Table 4 . It should be noted that the viscosity evaluated in the present work has got bit different unit than that used by other authors $[10,11,15]$. Considering Newtonian flow, the viscosity has the dimension of Pa.s. But as the rate constant of a chemical reaction assumes different dimensions depending on the order of chemical reaction, so the viscous resistance (or deformation rate) will assume different dimension depending on the flow behavior index (n). For the present study, the unit is Pa.s ${ }^{n}$.

From Table 3 it is seen that the viscosity of PP jute composites decrease with the increase in temperature. With the increase in the temperature, fluidity of the polymer increases. But the jute fibers as solid particles preserve their integrity during the flow of the composition irrespective of the temperature and they do not possess any fluidity. Thus for a given composition, with an increase in temperature, the viscosity decreases.

With the incorporation of fiber content, the small drag forces are integrated together to form high resistances to flow [14]. Thus, the observed viscosity increases, with the increase in the fiber content of all the melt composites (Table 3 and 4). As compared to the pure PP, for the jute fiber load of $30 \%$ in the composite, the increase of viscosity is around $122 \%$ at $220{ }^{\circ} \mathrm{C}$. George et al. [11] observed a viscosity-increase of around $294 \%$ for PE- pineapple fiber composite (with fiber content of 30\%) as compared to the pure PE. Maiti and Hasan [10] reported $160 \%$ increment in viscosity as the fiber concentration in PP-wood fiber composite is increased to $20 \%$. Nair et al. [15] showed a viscosity-increase of around $630 \%$ for PS-sisal fiber composite for the sisal fiber load of $30 \%$ in the composite.

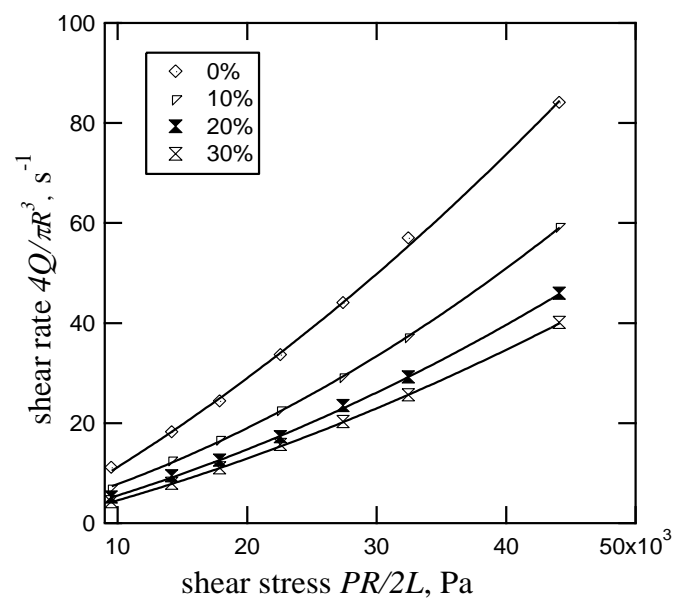

Fig. 3. Shear rate vs. shear stress at the wall for PP-jute composites with $0,10,20$ and $30 \%$ jute fiber content at the temperature of $220^{\circ} \mathrm{C}$. 


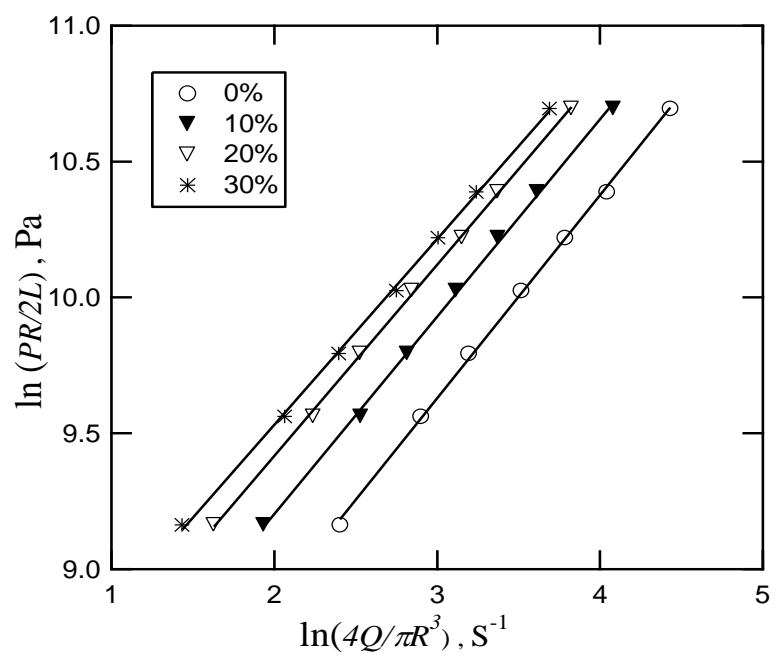

Fig. 4. Shear stress vs. shear rate at the wall for PP-jute composites with $0,10,20$ and $30 \%$ jute fiber content at the temperature of $220^{\circ} \mathrm{C}$.



Fig. 5. Shear stress vs. shear rate for PP-wood flour composites with 0, 3, 10 and $20 \%$ wood flour content at the temperature of $210^{\circ} \mathrm{C}$. The data were collected from Maiti et al. [10]. 




Fig. 6. Shear stress vs. shear rate for LDPE- short pineapple fiber composites with $0,10,20$ and $30 \%$ pineapple fiber content at the temperature of $125^{\circ} \mathrm{C}$. The data were collected from George $e t$ al. [11].

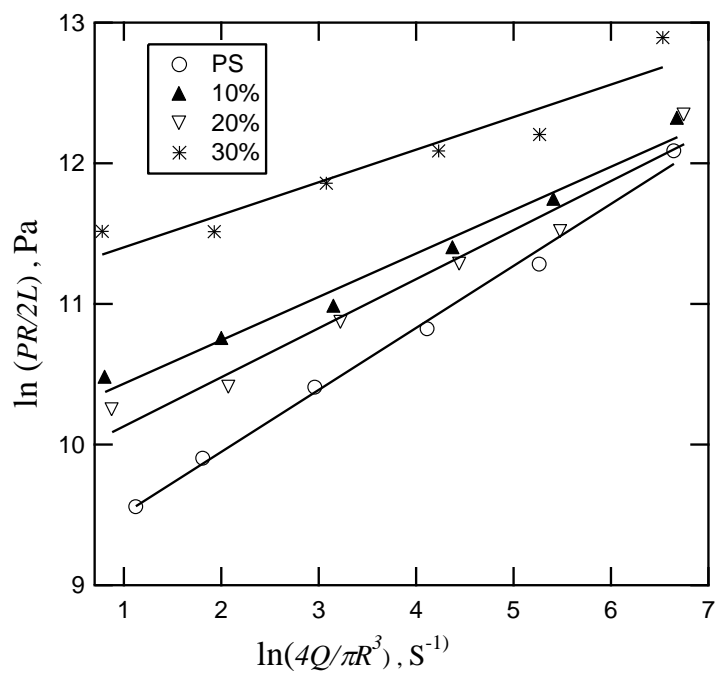

Fig. 7. Shear stress vs. shear rate for PS-sisal fiber composites with $0,10,20$ and $30 \%$ sisal fiber content at the temperature of $180^{\circ} \mathrm{C}$. The data were collected from Nair et al. [15]. 
Table 1. Flow behavior index ( $n$ ) of jute fiber- polypropylene composites with different fiber loading at temperature $220-260^{\circ} \mathrm{C}$.

\begin{tabular}{llll}
\hline Systems & FBI, $n$ at $220^{\circ} \mathrm{C}$ & FBI, $n$ at $240{ }^{\circ} \mathrm{C}$ & FBI, $n$ at $260{ }^{\circ} \mathrm{C}$ \\
\hline PP & 0.75 & 0.76 & 0.77 \\
PP+10\% fiber & 0.73 & 0.74 & 0.75 \\
PP+20\% fiber & 0.70 & 0.71 & 0.72 \\
PP+30\% fiber & 0.68 & 0.70 & 0.71 \\
\hline
\end{tabular}

Table 2. Flow behavior index, $n$ (measured from treated data) of different composites based on different fiber materials and polymer matrices $[10,11,15]$.

\begin{tabular}{llllll}
\hline Systems [10] & $n$ & Systems [11] & $n$ & Systems [15] & $n$ \\
\hline PP & 0.41 & LDPE & 0.41 & PS & 0.44 \\
PP+3wt $\%$ & 0.38 & LDPE+10wt $\%$ & 0.34 & PS+10wt $\%$ & 0.31 \\
PP+10wt $\%$ & 0.35 & LDPE+20wt $\%$ & 0.32 & PS+20wt $\%$ & 0.35 \\
PP+20wt $\%$ & 0.33 & LDPE+30wt $\%$ & 0.31 & PS+30wt $\%$ & 0.24 \\
\hline
\end{tabular}

Table 3. Viscosity $(\eta)$ of jute fiber-polypropylene composites with different fiber loading at various temperatures.

\begin{tabular}{llll}
\hline Systems & $\begin{array}{l}\text { Viscosity, } \eta\left(\text { Pa. }^{n}\right) \\
\text { at } 220^{\circ} \mathrm{C}\end{array}$ & $\begin{array}{l}\text { Viscosity, } \eta\left(\text { Pa.s }^{n}\right) \\
\text { at } 240^{\circ} \mathrm{C}\end{array}$ & $\begin{array}{l}\text { Viscosity, } \eta\left(\text { Pa.s }^{n}\right) \\
\text { at } 260^{\circ} \mathrm{C}\end{array}$ \\
\hline PP & $1.52 \times 10^{3}$ & $1.18 \times 10^{3}$ & $0.90 \times 10^{3}$ \\
PP+10wt\% fiber & $2.20 \times 10^{3}$ & $1.68 \times 10^{3}$ & $1.28 \times 10^{3}$ \\
PP+20wt\% fiber & $2.82 \times 10^{3}$ & $2.14 \times 10^{3}$ & $1.63 \times 10^{3}$ \\
PP+30wt\% fiber & $3.64 \times 10^{3}$ & $2.69 \times 10^{3}$ & $1.92 \times 10^{3}$ \\
\hline
\end{tabular}

Table 4. Viscosity $(\eta)$ (calculated from the treated data) of different composites based on different fiber materials and polymer matrices [10,11,15].

\begin{tabular}{|c|c|c|c|c|c|}
\hline $\begin{array}{l}\text { Systems } \\
{[10]}\end{array}$ & $\begin{array}{l}\text { Viscosity, } \\
\left(\text { Pa. }^{n}{ }^{n}\right) \\
\text { at } 210^{\circ} \mathrm{C}\end{array}$ & $\eta$ Systems [11] & $\begin{array}{l}\text { Viscosity, } \eta\left(\text { Pas. }{ }^{n}\right) \\
\text { at } 125^{\circ} \mathrm{C}\end{array}$ & Systems [15] & $\begin{array}{l}\text { Viscosity, } \eta\left(\text { Pa. }{ }^{n}\right) \\
\text { at } 220^{\circ} \mathrm{C}\end{array}$ \\
\hline PP & $5.03 \times 10^{3}$ & LDPE & $9.33 \times 10^{4}$ & PS & $7.03 \times 10^{3}$ \\
\hline $\mathrm{PP}+3 \mathrm{wt} \%$ & $7.48 \times 10^{3}$ & LDPE $+10 \mathrm{wt} \%$ & $19.98 \times 10^{4}$ & PS+10wt $\%$ & $19.96 \times 10^{3}$ \\
\hline $\mathrm{PP}+10 \mathrm{wt} \%$ & $10.79 \times 10^{3}$ & LDPE+20wt $\%$ & $25.65 \times 10^{4}$ & $\mathrm{PS}+20 \mathrm{wt} \%$ & $14.19 \times 10^{3}$ \\
\hline $\mathrm{PP}+20 \mathrm{wt} \%$ & $13.14 \times 10^{3}$ & LDPE $+30 \mathrm{wt} \%$ & $36.70 \times 10^{4}$ & $\mathrm{PS}+30 \mathrm{wt} \%$ & $51.19 \times 10^{3}$ \\
\hline
\end{tabular}

\subsection{Morphology of PP/jute composite}

The optical photograph of the surfaces of the extrudates of pure PP and $20 \mathrm{wt} \%$ jute fiber reinforced PP composites are shown in Fig.1a-b respectively, at the constant shear stress of $9.54 \times 10^{3} \mathrm{~Pa}$ and the temperature of $220{ }^{\circ} \mathrm{C}$. It is observed that the surface of the unreinforced PP is very smooth and uniform in diameter. But the reinforcement of fiber to the PP makes its surface very rough and it exhibits non-uniformity in diameter. Due to surface roughness, reinforced composite produces much friction to the wall of the flow channel it passes through than the pure PP does. Therefore, to maintain a given velocity gradient at the wall of the flow channel fiber-polymer composite needs higher shear stress 
than the pure PP. As a result, fiber reinforced composites show higher viscosity than that of the pure ones which is observed during the study.

Fig. 2a-b show the optical photograph of the cross-section of the extrudates of pure $\mathrm{PP}$ and $20 \mathrm{wt} \%$ jute fiber reinforced PP composites, respectively at the constant shear stress of $9.54 \times 10^{3} \mathrm{~Pa}$ and the temperature of $220^{\circ} \mathrm{C}$. In the case of pure PP, the surface is smooth and continuous but discontinuity in the surface is observed for fiber reinforced composite. From Fig. 2b it is clearly seen that the fibers are detaching out from its site during interception of the specimen, indicating poor adhesion between the fiber and the polymer matrix. This poor adhesion between the fiber and the polymer matrix is responsible for the increment of viscosity as well as the variation of other rheological parameter of fiber reinforced polymer composites compared to the unreinforced polymer [14].

\section{Conclusion}

Melt theological properties of jute fiber reinforced PP composites have been studied as a function of fiber content and temperature. All the composites exhibited non-Newtonian fluid nature and its shear stress versus shear rate relation can be represented by the power law equation, valid for the entire range of shear stress (1.0-4.4) $\times 10^{4} \mathrm{~Pa}$ studied. The shear stress and corresponding shear rate data have also been collected from literature and treated to measure the shear stress independent melt viscosity as in all the previous literature the viscosity is measured as shear stress dependent parameter. For all composites, PP-jute as well as the treated composites, the value of the power law index showed a decreasing trend with the increase in the fiber content keeping the temperature constant. As compared to the pure PP, for the jute fiber load of $30 \%$ in the composite, the increase of melt viscosity is around $122 \%$ at $220{ }^{\circ} \mathrm{C}$. But for a particular fiber concentration it was found to be decreased with the rise of temperature. For LDPE-short pineapple fiber composites $294 \%$ increase in viscosity is observed for the $30 \%$ pineapple fiber load in the composite as compared to the pure LDPE, the increase of viscosity is around $160 \%$ for $20 \%$ wood fiber load PP composite and $630 \%$ increment in viscosity is observed for $30 \%$ sisal fiber loading in PS at the given operational temperatures. Addition of jute fiber to polypropylene matrix creates irregularity and discontinuity in the polymer matrix which was evident from the optical photographs.

\section{References}

1. H. James and H. Dan, JOM: J. Min. Met. Mat. S. 58, 80 (2006).

2. A. Maguro, Angew. Makromol. Chem. 272, 99 (1999). https://doi.org/10.1002/(SICI)1522-9505(19991201)272:1<99::AID-APMC99>3.0.CO;2-C

3. K. Begum, M. A. Islam and M. M. Huque, J. Sci. Res. 7, 97 (2015). https://doi.org/10.3329/jsr.v7i3.23075

4. L. Bing, H. Yuhui, and C. Guangmin, J. Appl. Polym. Sci. 66, 1561 (1997). https://doi.org/10.1002/(SICI)1097-4628(19971121)66:8<1561::AID-APP17>3.0.CO;2-6

5. A. K. Rana, A. Mandal, B.C. Mitra, R. Jacobson, R. Rowell, and A. N. Banerjee, J. Appl. Polym. Sci. 69, 329 (1998). 
https://doi.org/10.1002/(SICI)1097-4628(19980829)69:9<1719::AID-APP5>3.0.CO;2-E

6. U. Hujuri, S. K. Chattopadhay, R. Uppaluri, and A. K. Ghoshal, J. Appl. Polym. Sci. 107, 1507 (2008). https://doi.org/10.1002/app.27156

7. M. Tazi, F. Erchiqui, and H. Kaddami, Polym. Composite 39, 29 (2018). https://doi.org/10.1002/pc.23898

8. O. Akampumuza, P. M. Wambua, A. Ahmed, W. Li, and X. H. Qin, Polym. Composite 38, 2553 (2017). https://doi.org/10.1002/pc.23847

9. S. Mohanty, S. K.Verma, and S. K. Nayak, J Appl. Polym. Sci. 99, 1476 (2006). https://doi.org/10.1002/app.22661

10. S. N. Maiti and M. R. Hassan, J. Appl. Polym. Sci. 37, 2019 (1989). https://doi.org/10.1002/app.1989.070370721

11. J. George, R. Janardhan, J. S. Anand, S. S. Bhagawan, and S. Thomas, Polymer 37, 5421(1996). https://doi.org/10.1016/S0032-3861(96)00457-0

12. R. K. Prasantha, K. C. N. Manikandan, S. Thomas, S. C. Schit, and K. Ramamurthy, Composite Sci. Technol. 60, 1737 (2000). https://doi.org/10.1016/S0266-3538(00)00057-9

13. P. V. Joseph, Z. Oommen, K. Joseph, and S. Thomas, J. Therm. Compos. Mater. 15, 89 (2002). https://doi.org/10.1177/0892705702015002446

14. M. A. Islam and K. Begum, Polym. Composite 36, 51 (2015). https://doi.org/10.1002/pc.22912

15. K. C. M. Nair, R. P. Kumar, S. Thomas, S. C. Schit, and K. Ramamurthy, Composites Part. A: Appl. Sci. Manufact. 31, 1231 (2000). https://doi.org/10.1016/S1359-835X(00)00083-X

16. E. E. Ferg and L. L. Bolo, Polym. Testing 32, 1452 (2013). https://doi.org/10.1016/j.polymertesting.2013.09.009

17. T. Bremner, A. Rudin, and D.G. Cook, J. Appl. Polym. Sci. 41, 1617 (1990). https://doi.org/10.1002/app.1990.070410721

18. R. B. Bird, W. E. Stewart, and E. N. Lightfoot, Transport Phenomena (John Wiley \& Sons, New York, 2002). 